\title{
Future Time Perspective in its Relationship to Academic Tasks Procrastination for Secondary Stage Students
}

Amr Mohamed Ibrahim Yousef

Educational Psychology Department, Faculty of Graduate

Studies of Educational, Cairo University, Egypt

\section{Abstract}

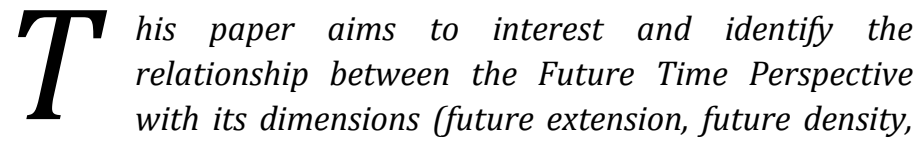
the degree of coherence, optimism/pessimism, future orientations, time speed), and academic tasks procrastination among a sample of public secondary stage students, to investigate the effect of some demographic variables (gender, academic specialization, academic grade) on the research variables. he present research used a descriptive approach based on the study of the phenomenon as it exists in reality, and contributes to describe it accurately and clarify its characteristics by collecting information, analysis and interpretation. Results showed and revealed that there was a percentage for the prevalence of academic tasks procrastination for public secondary stage students as follows (28.5 : 63.6) didn't delay their academic tasks continuously, (29.5 : 43.5) didn't prefer their academic tasks partially, (28.5: 31.3) preferred their academic tasks partially, There are no statistically significant differences in the item (21) for students choices (I promise myself I'll do something and then drag my feet), moreover, results revealed that there is a negative correlation statistically significant at the level (0.01) between a future time perspective degrees for six dimensions and degrees of academic tasks procrastination in public secondary stage students. Enriching the curricula at various stages, especially secondary, with topics that contribute to raising the levels of professional and academic ambition, and help to develop the perspective of the future of youth, in addition to educating young people subjects related to their future and developing a future plan in order to reduce the aggravation of unemployment among them, promote their positive vision, and reduce Negative outlook of the future.

Keywords Future Time Perspective, Time Speed, Academic Tasks Procrastination, Future Extension, Future Density, Optimism/ Pessimism 


\section{Introduction}

The Future Time Perspective is one of the concepts that explains the behavior of the individual, it depends on his ability to predict what will happen to him in the distant future, where every one's life is divided into past, present and future, and no one can separate between them to help one to live his present while being not affected by the past or the future, but some are directed towards one of those time frames, and this trend may be positive or negative.

The ability to think about the past, present and the future is the main feature of the human experience, understanding how to ponder on this time frames, and to make decisions accordingly it is an essential element in understanding the behaviors and emotions. The individuals vary in the way they interpret their lives over the time, these individual differences in information processing are pertinent to understanding the psychological issues that have increased dramatically in recent years.(Price, 2009).

The time perspective plays a role in stimulating human behavior, which makes people want to do things, and the word "perspective" refers to the representation of some events or things in the near or distant future, and that the ability to imagine the future and their future goals is what makes people to vary in the effort and struggle to achieve worldly interests in general. (Peetsma, 2000: 177).

Students who have a positive future prospective can do the hard work and exert more effort in their homework, unlike those with a negative future prospective (Peetsma, 2000). Although the majority of students give an initial impression of carelessness and indifference to education and the future, there are also those who clearly emphasize the goals of the future, and that these goals serve as guidelines for their current integration into the school and direct theme to the future, moreover these students have ideas of what they will do within ten years and they feel 
that they have much control over their future destinies, and that they become more positive towards school learning in general (McInerney, 2004).

(Leeks, 2006) refers that an individual's view of the future in the light of the past and the present - influences decisionmaking, and by distinguishing the range of underlying psychological effects within the current and future life framework, some individuals can pay attention to future outcomes, while others are interested in the present, accordingly, it is expected that those who are interested in the future will work and show healthy practices and seek to achieve future goals and expectations. On the other hand, those who are directed towards the present are increasingly hesitant about the immediate real-time factors and data, this what appears for example through Peer-to-peer practices.

(Keegan, 1986) states that the prospective of the future time is a complex process which is influenced by the process of maturity of the individual in which they acquires a greater appreciation of future possibilities, which in turn plays an increasing role in determining his behavior. The prospective of the future time is considered one of the cognitive components that changes dramatically during the adolescence stage, so studying the prospective of future times in this stage is an important and a logical step to deepen the understanding of the adolescent's behavior.

(Greene, 1986) has checked the Future-time perspective during the adolescence stage, and found out that older students have shown a greater extension of the future. In the research of (Padawer et al., 2007) the three-dimensional interaction between age, gender and educational level showed that age is the critical dimension on which the scores of the perspective of the future time differ. While both (Mello and Worrell, 2006) research indicates that there are no differences in the perspective of future times according to the age. 
(Wood, 1998) considers that the concept of a future-time perspective increases with children's growing age, but he has found that there are no differences in the future-time perspective of the adolescent sample due to age. According to (Silverman, 1996) the gradual development of children's language clearly contributes to the process of understanding of the future, he also added that children between (3) to (5) years are able to separate past, present and future in their expressive language, where the younger children have a short-term future perspectives which increases according to their growing up.

(Leeks, 2006) adds that the adolescence stage has the most prominent effect on the evolution of the perspective of the future, as the individual at this specific stage goes through exciting transition and development stages in the process of the preparation for what is to come.

The results of (Honora, 1998) showed that the ongoing future perspective helped to provide some adolescents with motivation and academic performance contrary to other adolescents with a current future time perspective, and that a continuous future time perspective helped achieve long-term goals, therefore, it is expected that individuals with an extended future perspective will be more motivated, enthusiastic about their current activities, effort-driven and better performance in subsequent tests (Simons et al., 2004).

(Honora, 1998) found that males have more awareness of the importance of the current goals than females, and they believe that hard work is the means to achieve goals more than girls do. Also, they were more aware while discussing their goals and expectations of the future than females, and that male feelings clearly influence their perspective of the future compared to females, and that their tendency to be optimistic and pessimistic on the basis of their sensitive feelings towards the surrounding events has played an influential role on their 
future outlook, The results of research of (Zimbardo et al., 1997) showed that males are more oriented towards the present and are more likely to take risks than females, while females are more oriented towards the future.

(Rodriguez, 1998) found that there are no differences between males and females in the future perspective, both males and females could express themselves better in their perspective of the future, Research results of (Mello and Worrell, 2006) found that females reported less negative attitudes towards the future than their male counterparts, while the research results of (Mello et al., 2009) found no differences between male and female adolescents in the future perspective as each of them presented quite similar perceptions about the past, present and future .

In addition (Peetsma and Van der Veen, 2011) stated that the gender variable had more a profound impact on the longterm future perspective of social relations than other fields of life, such as school, career and leisure time. Both (Lasane and Jones, 2000) confirmed that the present time orientation is represented in the behavior of procrastination, and that the students who are oriented towards the present have a simple social background compared to future-oriented students, that the procrastination behavior is associated with a strong tendency to participate in funny short-term activities, those procrastinators who are oriented towards the present are less satisfied, unlike their future-oriented peers in setting academic goals, so early attention to procrastination behaviors may help researchers explore the psycho-social behavior of individuals with a present time orientation.

(Bosato, 2001) predicted that students oriented to the present are more likely to procrastinate than students with a future orientation and this is consistent with the assumption that future-oriented students are more specific to their own destiny 
than those with other temporal orientations. The procrastination behavior is considered a common phenomenon that affects the lives of individuals, however, some individuals may be considered incurable procrastinators and they are exposed to negative effects as a result of this procrastination, as they are likely to have a short sense of the future compared to nonprocrastinators. (Deyling, 2008).

Despite the fact that procrastination behavior occurs in all kinds of daily tasks, academic procrastination is a very common phenomenon among students, harmful to the academic progress and success, which justifies the research on such abnormal behavior. The adolescents spend a great deal of their time either at school or in practicing their school activities, whereas the school has limited time for tasks, research work and examinations (Rosário et al., 2009).

There is no doubt that procrastinating tasks or duties is sometimes acceptable, as all students may be forced to procrastinate their duties until later, especially when unforeseen circumstances occur, due to some changes in their work plans, yet some students often procrastinate the termination of their duties, which makes them feel guilty about wasting time and losing opportunities, and this repeated procrastination is described as problematic and we can call it a procrastination.

The procrastinators know that they have to perform an activity, and they may want to do so, but they fail to push themselves to start or finish activities within the desired or expected time frames (Jaradat and Rost, 2004). (Asikhia, 2010) mentioned that procrastination reflects the individual's repeated failure to do what should be done to reach his goals.

Procrastination is a complex phenomenon, with gradient levels ranging from simple to the incurable one, and it has a negative impact on many aspects of life such as: education, management, health, social relations, and financial transactions, 
personal and professional development. The different prevalence of academic tasks procrastination among students in schools and universities is due to many personal, demographic factors and others.

(Solomon and Rothblum, 1984) found that the percentage of the procrastinators due to fear of failure extends from $(6.3 \%)$ to $(14.1 \%)$, while the hatred of the task extends from $(19.4 \%)$ to (47\%), In fact there are many university students who procrastinate their duties, and the percentage is divided between the postponement their tasks as follows: (46\%) for written tasks, $(30.1 \%)$ for weekly reading duties, $(27.6 \%)$ for study for the test, (23\%) for accomplishing academic tasks, (10.6\%) for administrative tasks, (10.2\%) for school activities in general. (Solomon \& Rothblum, 1984: 508).

(Jiao and Onwuegbuzie, 1999) found that more than (50\%) university students tend to procrastinate their duties. While Lee, (1999) found that more than (70\%) of them procrastinate their school work until the last minute. The results of the research by (Balkis and Duru, 2009) indicated that about half of the university students experience different levels of difficulties in academic procrastination behavior. Researchers are still examining the prevalence of the procrastination phenomenon in the academic fields, where research results of (Onwuegbuzie, 2000:13-14) indicated that (41.7\%) of the students acknowledged that they procrastinate the writing and completion of academic assignments, and (60\%) procrastinate the weekly reading, and (39.3\%) procrastinate studying for the tests.

Abd Al Dayem Abdul Salam, (2010: 49) found that the prevalence of the procrastination behavior for academic assignments among middle and high school students is between $(20 \%)$ and $(40 \%)$ in light of global standards.

The procrastination behavior is clearly reflected in the deliberate and repeated procrastination of the required work and study tasks, both in terms of starting or finishing them and 
not completing them on time as expected. The results of research (Jaradat and Rost, 2004, Jiao and Onwuegbuzie, 1999, Keegan, 1986)Hassan Ahmed Omar Abd Allah (2008) showed that a high percentage of students acknowledged the existence of educational problems represented in the incurable Academic Procrastination such as: procrastinating duties and assignments, writing the required research within the specified time, as well as procrastinating the recollection permanently until short time before the exam, and they cannot prepare for the exam appropriately.

The results of research (Akinsola et al., 2007, Ferrari et al., 2009, Liu, 2010) show that there are no differences between males and females in procrastination behavior, which indicates that such behavior is common among students of both genders. While research results of (AbdelDayem Abdeslam, 2010), (Reasinger and Brownlow, 1996, Steel, 2007) showed that females procrastinate more than males. While the results of research (Balkis and Duru, 2009, Özer et al., 2009, Van Eerde, 2003, Yong, 2010) found that males procrastinate more than females. Abdul Rahman Mohammed Moselhi and Nadia Al-Sayed Al-Husseini, (2004: 114) found that there are statistically significant differences between the students of the university in the total score of academic procrastination and both the cognitive and behavioral aspects in favor of the students.

The results of the research of (Freih Owaid Al-Enezi and Mohammed Daghaim Al-Daghaim, 2003: 131) show that the relationship between age and academic procrastination did not reach the level of statistical significance, and accordingly the academic procrastination can appear at any age. Ferrari et al., (2009: 302) concluded that there were no significant age differences in any form of the incurable procrastination (procrastination in decision-making, avoidance procrastination and exclusionary procrastination). Rosário et al., (2009: 122) research results indicate that academic procrastination levels rise with grade level. Whereas (Balkis \& Duru, 2009: 23) found 
that with the growing age, the level of the academic procrastination behavior decreased.

Yong, (2010: 62) found that older students procrastinate more than younger students. (Sayyid Abd al-Dayem Abd alSalam, 2010: 50) also found that the rate of procrastination of the academic tasks at the secondary stage is higher in the second grade than in the first grade. Attia Attia Mohammed, (2007: 92) found that there are statistically significant differences between the students of the Faculty of Arabic Language and the students of the Faculty of Sharia at King Khalid University in Saudi Arabia in the total degree of academic procrastination and both the cognitive and behavioral aspects in favor of the students of the Faculty of Arabic Language.

The results of the researches of (Hassan Ahmed Omar Abdullah, 2008: 288) and "Liu" (Liu, 2010: 30), how that there are no significant differences in the behavior of academic procrastination for the students according to the variable of specialization, which indicates that procrastination behavior is common for both genders with the different specializations. Yong, (2010: 62) concluded that business students procrastinate writing their required classroom research more than the engineering students. Elsayed Abd Eldaym,(2010) examined the prevalence of procrastination behavior among students of the scientific and literary sections at the secondary stage, he found that the rate of academic procrastination is higher among the students of the scientific department than among the students of the literary section.

\section{The idea that the researcher will address}

It is clear from the foregoing that the results of the research presented a contradiction in determining the age differences as well as the differences between the two types and differences in academic specialization in the two research variables (perspective of future time and procrastination of the academic tasks), while the class variable was addressed at a very low level 
of research. Therefore, it was necessary to consider the impact of these variables on the two research variables.

It is clear that the perspective of the time of the future has been viewed from two angles; The first angle is a cognitive aspect that dominates the emotional side, and this is related to the person's construction of goals and placing them in the context of the future either (current/near/distant) therefore this is related to how the person considers the life he expects to have, what means"I am in the future", with my goals and ambitions, and this is the trend which was adopted by (Mr. AbdelDayem Abdeslam, 1995) in his research. The other angle is a trend that looks at the image of the future "the future in which I will be" where the emotional dominated the cognitive side, which is represented in describing the future events in reflection of the past and the present events, in other words the phrases here will be events and situations and not objectives as they are in the first. Trend. The researcher will follow the second trend.

\section{Justification for sample selection}

Most of the research focus on procrastinating the academic tasks particularly among students, especially university students, but we find it necessary at the present time to consider the procrastination of academic tasks among the high school students, to whom the full responsibility of performing the academic tasks is transferred after the previous stages of study in which parents and teachers share it with them. They also face constant pressure being asked to complete their tasks early, so some of them, even most of them resort to procrastinating or delaying the completion of those tasks till the last possible moment, which may lead to increasing of the pressure on them, and this negatively affects their educational and even psychological aspects.

The image derived from the previous research on the volume and prevalence of the behavior of procrastinating the academic tasks among students, especially secondary school 
students at different stages in this current age is a cause of concern, and assures the need to examine its causes and the characteristic variables of the procrastinators in an attempt to understand this phenomenon and what is associated to it, which helps to develop plans and programs to reduce this ill behavior.

Although the concepts of the future time perspective and the procrastination of academic tasks are common in psychological research in general and in educational contexts in particular in Western societies, in our Egyptian society they are hardly there - within the limits of the researcher's knowledge - of the research fields, whether educational or any other ones despite their obvious importance and impact on human behavior in general and on educational performance in particular.

\section{Methodology}

\section{Participants}

Based on the nature of the research, the objectives and the data seek to be obtained to learn the relationship between the two research variables (perspective of the future-time, procrastination of academic tasks) for high school students. Based on the questions that the research tried to answer, the research used the descriptive approach that depends on the study of the phenomenon as it actually exists, it contributes to its accurate description and explains its characteristics by collecting, analyzing and interpreting the data, and then applying the results in its light. This approach doesn't stop at the limit of collecting the data related to the educational and psychological phenomena, tabulating and organizing it in order to investigate its various aspects, but it also draws conclusions that contribute to understanding the reality through analyzing it and reaching meaningful generalizations by which the research increases the balance of knowledge. The exploratory sample of the research consisted of (320 Male and 411 Female of the secondary school students). The mean score of the age for this sample was: both male and female was (16) years and four months with a standard deviation (S.D) of (884.0). The data of this sample was used to 
calculate psychometric characteristics (see Table1). (Validation of stability, internal consistency and honesty).

Table 1. Numerical description of the final search sample

\begin{tabular}{|c|c|c|c|c|c|c|c|}
\hline Sex & & Phase & & Phase & & Phase & Total \\
\hline & 1 & & 2 & & 3 & & \\
\hline Male & & 126 & & 146 & & 48 & 320 \\
\hline Female & & 181 & & 166 & & 64 & 411 \\
\hline Total & & 307 & & 312 & & 112 & 731 \\
\hline Percent & & 15.64 & & 17.09 & & $5.98 \%$ & 12.91 \\
\hline age & $\%$ & & $\%$ & & & & \\
\hline
\end{tabular}

The researcher focuses on the secondary stage for several reasons:

1) The majority of previous research focuses on university students and few on high school students which made the researcher go deeper to know the characteristics of students at this stage because of their significant implications on their future, where their future thinking is formed at that stage.

2) The secondary stage is considered the decisive stage in the student's life where his personality is formed, and his distinctive way in facing future challenges is completed by

3) The secondary stage was chosen because the students are more specific to what they wish to be in the future and their perceptions towards their future during it the student uses all means that help him achieve his long-term future goals.

As this stage is one of the most important stages in the life of the student and the first steps he takes to the best future he wants and seeks to achieve.

\section{Measures}

The research was based on two tools, a measure of the perspective of the future time that was designed after reviewing the theoretical framework and the previous research related to this field. In the light of the use of the metrics used by this research, which were concerned with measuring the perspective 
of the time of the future1 (see Table 2). After looking at the previous measures related to the subject of the research, the researcher incorporated the dimensions (the rule of optimism, direction/emotion, outlook, optimistic outlook, and pessimism) under the name (optimism/pessimism), and therefore identified six dimensions that the measure can now address. They are: future expansion, future density, and degree of cohesion, optimism/pessimism, future trends, and the speed of time

These metrics do not meet the purpose of the current research, and differ in their characteristics from those of the research sample, so a measure of the future time perspective is prepared to commensurate with the characteristics of the research sample and its purpose - the second tool is the measure of procrastination of the academic tasks (Tuckman, 1990), it was designed for measuring the procrastination of the academic tasks and how it is related to the overall self-efficacy, and a behavioral measure to procrastinate a performance task in a psychology course called a self- regulated performance task

The measure had (72) words in the light of the likert method, covering;

- General self-description of the tendency to procrastinate or leave things aside.

${ }^{1}$ DALTREY, M. 1982. The development and evaluation of a future time perspective instrument (Doctoral dissertation, University of Colorado at Boulder, 1982). Dissertation Abstracts International, 43, 2315B, DEYLING, E. A. 2008. The effect of priming death anxiety on future time orientation and procrastination, HEIMBERG, L. K. 1963. The measurement of future time perspective, HUSMAN, J. \& SHELL, D. F. 2008. Beliefs and perceptions about the future: A measurement of future time perspective. Learning and Individual Differences, 18, 166-175, RODRIGUEZ, M. 1998. Future time perspective and academic achievement level among Puerto Rican children, SEYMOUR, R. 1992. Constructing a personal future time perspective, SHELL, D. F. \& HUSMAN, J. 2001. The multivariate dimensionality of personal control and future time perspective beliefs in achievement and selfregulation. Contemporary educational psychology, 26, 481-506, STAHL, S. T. 2009. Health promotion during midlife: The influence of internal health locus of control and future time perspective, West Virginia University. 
- The tendency to feel the difficulty of doing unpleasant things.

- The tendency to blame others for the hardships to which the individual is exposed.

Table 2. The scales associated with the future time perspective scale in the field

Researcher's name and year of Scale dimensions
publication

(Heimberg, 1963)

Time flow, the primacy of optimism, the rejection of challenges, the degree of future construction, and the time horizon.

\begin{tabular}{|c|c|}
\hline (Daltrey, 1982) & $\begin{array}{l}\text { Future extension, future } \\
\text { cohesion, density, } \\
\text { direction/emotion. }\end{array}$ \\
\hline (Seymour, 1992) & $\begin{array}{l}\text { Future extension, cohesion, } \\
\text { direction/emotion, future trends, } \\
\text { temporal integration, and future } \\
\text { images. }\end{array}$ \\
\hline (Shell and Husman, 2001) & Bonding, parity (value). \\
\hline (Husman and Shell, 2008) & $\begin{array}{l}\text { Future extension, parity, } \\
\text { interdependence, and the speed of } \\
\text { time. }\end{array}$ \\
\hline (Stahl, 2009) & $\begin{array}{l}\text { Beliefs about time, opportunities, and } \\
\text { goals that can occur in the future }\end{array}$ \\
\hline
\end{tabular}

\section{Results}

\section{The first hypothesis}

The results of the study are presented according to the assumptions imposed by the researcher and the first hypothesis states: There are no statistically significant differences between the average grades of both males and females in the measure of the perspective of the future time and its dimensions among the students of the high school. To test the validity of this hypothesis, the researcher used the T-test in two independent samples, to calculate the statistical significance of the differences between the average male and female grades in the perspective of the time of the future and its dimensions, see table 3. 
Table 3. Results of the T-test indicated to the differences between the averages of the total grades of males and female secondary students in the perspective and dimensions of the future time

\begin{tabular}{|c|c|c|c|c|c|c|c|c|}
\hline Variable & 320 & Male & & Female & 411 & & & \\
\hline $\begin{array}{l}\text { Future-Time } \\
\text { Perspective }\end{array}$ & & ${ }^{I} .0$ & ! & ${ }^{1} .0$ & ! & 1 sig & -Test & ${ }^{i}$ \\
\hline \multirow[t]{2}{*}{ Future extension } & & 8 & $:$ & 1 & : & 1 & & ( Non- \\
\hline & .09 & .985 & .06 & .995 & .001 & on-sig & .196 & sig \\
\hline Future density & 1.04 & $\begin{array}{l}: \\
.203\end{array}$ & : 0.97 & $\begin{array}{l}: \\
.146\end{array}$ & $\begin{array}{l}: \\
.505\end{array}$ & on-sig & .246 & $: 0.05$ \\
\hline \multirow[t]{2}{*}{ Degree of consistency } & & $!$ & & $!$ & $:$ & 1 & & : Non- \\
\hline & .42 & .519 & .58 & .540 & .003 & on-sig & .356 & sig \\
\hline Optimism/pessimism & & 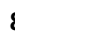 & $:$ & $!$ & : & 1 & & I Non- \\
\hline & .96 & $q^{.177}$ & $:^{.01}$ & $i^{.091}$ & $i^{.675}$ & $:^{\text {on-sig }}$ & .348 & $\begin{array}{l}\text { sig } \\
\text { ( Non- }\end{array}$ \\
\hline Future trends & .23 & .101 & .12 & .300 & .981 & on-sig & .674 & sig \\
\hline \multirow[t]{2}{*}{ The speed of time } & & 1 & $:$ & : & $:$ & $\vdots$ & & : 0.01 \\
\hline & .12 & .048 & .72 & .896 & .178 & on-sig & .777 & \\
\hline \multirow[t]{2}{*}{ Total Score } & & $\iota$ & : & $،$ & 8 & 1 & & : Non- \\
\hline & 9.86 & .979 & 9.19 & .093 & .473 & on-sig & .173 & sig \\
\hline
\end{tabular}

The results of the previous table show that the previous hypothesis was partially correct, as the results indicated that:

- There are no statistically significant differences between the averages of total grades in males and females on the future time perspective scale.

- There are no statistically significant differences between the averages of both males and females in four dimensions of the future time perspective: (future extension, degree of cohesion, optimism/pessimism, and future trends.

- There are statistically significant differences at the indicative level (0.05) between the average grades of both males and females in the distance (future density) in favor of the average male score.

- There are statistically significant differences at the level of significance $(0.01)$ between the average grades of both males 
and females in the distance (speed of time) in favor of the average male score.

By comparing the results of this hypothesis with those of the previous research, it is clear that these results are consistent with the results of each of the (Rodriguez, 1998, Silverman, 1996) Where the researcher found that there are no differences between males and females in the perspective of the future time, as this finding is consistent with the results of a research of (Athawale, 2004, Mello et al., 2009, Phan, 2009), The results of this hypothesis vary with the results of the research of (Mello and Worrell, 2006, Zimbardo et al., 1997). It is consistent with the findings of (Rodriguez, 1998), where it found that there are no differences between males and females in the future time perspective, and that the relatively large difference between them is in the future extension, followed by future density, followed by a future point of view.

According to research of (Ronan, 1997) the females expect marriage and motherhood at younger ages than males, and females are exposed to more family-related events than males, while males have a longer extension of the future time perspective than females. Differences between males and females also show how realistic the goals are: while females are in tune with daydreams, unrealistic life and lacking future fantasies with no plans, males tend to have more realistic goals and a better degree of planning.

The results of this hypothesis differ partly from those of the research of (Honora, 1998) in which males were found to be more aware while discussing their goals and future expectations than females, the influence of males' feelings clearly influence their perspective on the future time compared to females, and that their tendency to be optimistic and pessimistic on the basis of their sensitive feelings about the events surrounding them may play a role in influencing their outlook. 
The results of this hypothesis also differ with those of research (Peetsma, 2000, Van Eerde, 2003), where they concluded that the type variable had a profound impact on the long-term future perspective of social relations without other aspects of life, such as school, career and leisure.

The results of this hypothesis can be explained by the fact that both males and females have similar perceptions and concepts about the time of the future, indicating that what is applied to males is applied to females, because life in the future is based on the participation of the two species, as female students have a deeper view of the time of the future, and also male students, due to the nature of the society in which each of them lives.

This can also be explained by the decreasing role played by parents at the present time, where the secondary school stage is a period of adolescence in which the student is associated with his peers, and is greatly influenced by them, the student who has an idea of his future can equally affect all his peers in the same Secondary school, indicating equal male and female view of the future, It can be explained that there are no statistically significant differences between the averages of both males and females in the future extension dimension, that each has a similar and similar ability to shed their ideas in the long term in the future in a society characterized by opportunities for all both in the light of neutral criteria (i.e. lack of to distinguish between males and females), they both think about what it will be in the years to come. It can be explained that there are no statistically significant differences between the averages of both males and females in the degree of cohesion, in that each of them has the same professional and family interests, but females feel more responsible for family planning, while males are responsible for professional planning, and this is consistent. With research (Schmidt et al., 1978), it is also because the planning of both male and female students for the goals of the future is the same, both 
of which make an effort to achieve their future goals through organization and follow-up.

The lack of statistically significant differences between the averages of both males and females in the dimension of optimism/pessimism is due to the agreement of the rates of optimism and pessimism among students. It is of great importance to their future, and that every success they achieve today may be a step to success in the future, and on the other hand, we find them afraid to go into the unknown future events, and this makes them see their future unknown, and they may see that future events are only a repetition of the events of the past. This is also due to the events that the Egyptian society is going through such as the difficult political or the economic events, especially after the events of the January 25 revolution.

It can be explained that there are no statistically significant differences between the averages of both males and females in the dimension of future directions, that both males and females see themselves moving quickly towards the future, in order to do so, and believing that it will be the best, as they feel that the experiences and successes of the present it's their way to the future, and that's through being in an age of information progress (the information age), globalization (opening up to the world), and this requires them to do more to achieve their future personalities, which makes them move quickly towards future events, and always move forward, taking the advantage of the present to achieve their future goals.

While there are statistically significant differences at (0.05) between the average grades of both males and females in the future density dimension in favor of the average male grades, due to the fact that males have the ability to set their goals, and appreciate the future life events they may experience, as they expect that adjust with with their future ideas and aspirations compared to females, and this may be illustrated by their 
awareness of the responsibilities they will have in the future as a result of the initiative to achieve a successful family future.

There are also statistically significant differences at (0.01) between the average grades of both males and females in the dimension of time speed in favor of the average male grades, due to the fact that males expect to accomplish much of their work and future plans more than females, and this can be explained by the nature of community life which each of them has, where they require males to perform their tasks and duties in addition to their other tasks especially that are related to the family, in order to live a decent family life based on struggle and exerting more effort. They will be the heads of future families, so they are always interested in every decision they make in dealing with the vocabulary of the future and its data. Unlike females whose focus is based on their study tasks only with a few family burdens at the present time. The differences in the speed of time in favor of males, can be due to the fact that males have realized, during their planning to achieve their future goals, the time value they will spend studying the university subjects, compulsory conscription, and then the time required to prepare for a new family life that requires the search for a suitable, rewarding job that ensures the stability of the family life he/ she aspires to.

\section{The second hypothesis}

The results of the study are presented in accordance with the second hypothesis set by the researcher, which states "There are no statistically significant differences in the future time perspective and its dimensions due to the grade $(1 / 2 / 3)$ of the secondary school students. To test the validity of this hypothesis, the researcher used the One Way ANOVA analysis test to measure the statistical significance of the differences between the average grades of high school students from grades $(1 / 2 / 3)$ in the perspective of the future time and its dimensions. (See Table 4.) 
Table 4. Results of the Anova analysis test to indicate the differences between the average grades of high school students in the perspective of the future time and dimensions of the classroom Variable $\begin{array}{llll}\text { Sum } & d & \text { Mea } & F\end{array}$

\begin{tabular}{|c|c|c|c|c|c|c|c|c|c|c|}
\hline & & \multicolumn{2}{|c|}{ of Squares } & $f$ & \multicolumn{3}{|c|}{ n Squares } & & \multicolumn{2}{|r|}{ g } \\
\hline \multirow[t]{5}{*}{$\begin{array}{l}\text { Future } \\
\text { extension }\end{array}$} & $\begin{array}{c}\text { Between } \\
\text { Group }\end{array}$ & & 5.119 & & 2 & \multicolumn{2}{|r|}{2.55} & \multirow{5}{*}{646} & \multirow[t]{2}{*}{0.} & \multirow[t]{2}{*}{$\operatorname{sig}^{N}$} \\
\hline & Within & & 2885.1 & & 7 & \multirow{3}{*}{3} & \multirow{3}{*}{3.96} & & & \\
\hline & Group & 82 & & 28 & & & & & & \\
\hline & Tota & & 2890.3 & & 7 & & & & & \\
\hline & 1 & 01 & & 30 & & & & & & \\
\hline \multirow{6}{*}{$\begin{array}{l}\text { Future } \\
\text { density }\end{array}$} & Between & & 13.840 & & 2 & & 6.92 & \multirow{6}{*}{462} & \multirow[t]{6}{*}{1.} & \multirow{6}{*}{ sig ${ }^{\text {Non- }}$} \\
\hline & Group & & & & & 0 & & & & \\
\hline & Within Group & & 3445.7 & & 7 & & 4.73 & & & \\
\hline & & 99 & & 28 & & \multirow[t]{3}{*}{3} & & & & \\
\hline & Tota & & 3459.6 & & 7 & & & & & \\
\hline & I & 39 & & 30 & & & & & & \\
\hline \multirow{6}{*}{$\begin{array}{l}\text { Degree of } \\
\text { consistency }\end{array}$} & Between & & 10.921 & & 2 & & 5.46 & \multirow{6}{*}{336} & \multirow[t]{6}{*}{2.} & \multirow{6}{*}{ sig ${ }^{\text {Non- }}$} \\
\hline & Group & & & & & 1 & & & & \\
\hline & Within & & 1701.7 & & 7 & & 2.33 & & & \\
\hline & Group & 71 & & 28 & & \multirow[t]{3}{*}{8} & & & & \\
\hline & Tota & & 1712.6 & & 7 & & & & & \\
\hline & 1 & 92 & & 30 & & & & & & \\
\hline \multirow{6}{*}{$\begin{array}{r}\text { Optimism } \\
\text { / pessimism }\end{array}$} & Between & & 18.589 & & 2 & & 9.29 & & 2. & Non- \\
\hline & Group & & & & & 5 & & 059 & & sig \\
\hline & Within & & 3286.3 & & 7 & & 4.51 & & & \\
\hline & Group & 44 & & 28 & & 4 & & & & \\
\hline & Tota & & 3304.9 & & 7 & & & & & \\
\hline & 1 & 33 & & 30 & & & & & & \\
\hline Future & Between & & 20.518 & & 2 & & 10.2 & & 2. & Non- \\
\hline trends & Group & & & & & 59 & & 099 & & sig \\
\hline & Within & & 3558.4 & & 7 & & 4.88 & & & \\
\hline & Group & 53 & & 28 & & 8 & & & & \\
\hline & Tota & & 2578.9 & & 7 & & & & & \\
\hline & I & 71 & & 30 & & & & & & \\
\hline The speed of & Between & & 67.705 & & 2 & & 33.8 & & 8. & 0 \\
\hline time & Group & & & & & 53 & & 884 & & .01 \\
\hline & Within Group & & 2773.3 & & 7 & & 3.81 & & & \\
\hline & & 72 & & 28 & & 0 & & & & \\
\hline & Tota & & 2841.6 & & 7 & & & & & \\
\hline & I & 77 & & 30 & & & & & & \\
\hline Total Score & Between & & 299.94 & & 2 & & 149. & & 2. & Non- \\
\hline & Group & 1 & & & & 971 & & 343 & & sig \\
\hline & Within Group & & 46593. & & 7 & & 64.0 & & & \\
\hline & & 774 & & 28 & & 02 & & & & \\
\hline & Tota & & 46893. & & 7 & & & & & \\
\hline & $\mathrm{I}$ & 715 & & 30 & & & & & & \\
\hline
\end{tabular}

The results of the previous table showed that the second hypothesis is partially correct, as the results indicated that there 
are no statistically significant differences between the averages of grades of secondary school students that due the grade $(1 / 2 / 3)$ in the overall degree of the future time perspective scale. In view of the results of previous research, this finding is consistent with the results of the research (Mello and Worrell, 2006) where they found that there was no correlation between age and the perspective of the future. It differs with the early results of the research according to (Piaget, 1954) \& (Padawer et al., 2007).

The results also indicated that there are no statistically significant differences between the average grades of the secondary school students due to the grade $(1 / 2 / 3)$ in five dimensions of the future time perspective which are : (future extension, future density, degree of cohesion, optimism/pessimism, and future trends). There are statistically significant differences at the level of significance (0.01) between the grades of secondary students due to the grade $(1 / 2 / 3)$ in the dimension of (speed of time).

Comparing the results of previous research, this result is partly consistent with those of a research (Greene, 1986), which showed that older students have greater extension for the future, and the more cognitively advanced students demonstrated that they have better ability to visualize a range of events in the far future. However, none of the older or cognitively advanced students imagined a larger number or group that was more stable and consistent about future events than their counterparts did. These results are also consistent with those of (Wood, 1998), which showed that although the concept of an extension of the perspective of the future time increases with children's age, it has found no differences in the future-time perspective of the adolescent sample due to the age.

These results are different from those of (Silverman, 1996), where younger children are considered to have short-term 
future perspectives, which are developed with their growing age . The results also indicated that children may have a different concept of the relationship between the past, the present, and the future is than the adults'.

It can be explained that there are no differences in the overall outlook among the three grades of the perspective of the future time due to the age convergence between them, and the curriculum that lacks the analysis of the perception of the value of the future, and the absence of a clear plan from the state for students to study. This is evidenced by the confusion between the nature of the curriculum and the grades of subjects. Private lessons on the student and the family blinded the family from everything except getting out of the high school cocoon. The family and their children looked at the students under their feet and did not look to the future with a purposeful and insightful look

The reason is that there are no statistically significant differences between the average grades of secondary students due to the grade (I / II / III) in the future extension dimension, because all students of that stage think about their future, and what they will be after the secondary the class in which they study.

The absence of statistically significant differences between the average scores of both male and female secondary school students due to the grade (I / II / III) in the dimension of optimism / pessimism, because all students may have a similar outlook, whether positive or negative towards Future events, the researcher believes that the nature of the political and economic conditions experienced by the Egyptian society, especially before and after the revolution (25) January, reflect the students' view of their future

The absence of statistically significant differences between the average scores of both male and female secondary school 
students due to grade (I / II / III) in the future directions, because the first grade secondary students feel that they are moving quickly towards their future, they think when they will move To a higher class, as well as to second-graders, and thirdgraders, who are thinking about when to move to university, where a new life begins with a future outlook

While there are statistically significant differences at the significance level (05.0) between the mean grades of the first and second secondary grades in the dimension (speed of time) in favor of the average grades of the first secondary graders, and the presence of statistically significant differences at the level of significance $(05,0)$ between the mean grades of the first and third grade secondary students in the dimension (speed of time) in favor of the average grades of the first secondary graders, and the absence of statistically significant differences between the mean grades of grades two and third grade secondary in the dimension (speed of time)

That the second and third graders have adapted to the school, settled the subjects, and settled their matters, it is no longer a lot to think about their place in school, after a few months they will be in a certificate for the students of the second grade, or move to a university stage for the third grade students, Third grade students are less likely to be disinterested in the speed of time. As for the first year secondary students, they have a feeling that they have two and a half years to graduate, which makes them think how to expect future events, how to plan for them, and calculate them, because it is good for them, and for the newness of the completion of an earlier stage (preparatory stage).

\section{The Third hypothesis}

There are no statistically significant differences between the average male and female grades in the procrastination of academic tasks for general secondary school students. To test the 
validity of this hypothesis, the researcher used the T-test in two independent samples, to calculate the statistical significance of the differences between the average male and female grades in deferral of academic tasks, see Table 5.

Table 5. Results of the T-test to indicate the differences between the averages of the total grades of males and female secondary school students in the scale of procrastination of academic tasks

\begin{tabular}{|c|c|c|c|c|c|c|c|c|}
\hline Variable & 320 & Male $=$ & & Female & $=411$ & & & \\
\hline $\begin{array}{l}\text { Academic } \\
\text { Tasks } \\
\text { Procrastination }\end{array}$ & &.$D$ & $S$ &.$D$ & $S$ & sig & -Test & ig \\
\hline \multirow[t]{2}{*}{ Total Score } & & & 1 & 1 & 1 & I No & & I No \\
\hline & 6.19 & 3.891 & 6.46 & 3.933 & .012 & n-sig & .267 & n-sig \\
\hline
\end{tabular}

It is clear from the previous table that the third hypothesis is correct, with the results indicating that there are no statistically significant differences between the averages of both males and females in the overall degree on the scale of the procrastination of academic tasks. In view of the results of previous research, the results of this hypothesis are consistent with the results of the research of (Akinsola et al., 2007, Ferrari et al., 2009, Liu, 2010, Solomon and Rothblum, 1984). While the results of this hypothesis differ with search results (Balkis and Duru, 2009, Brownlow and Reasinger, 2000, Özer et al., 2009, Reasinger and Brownlow, 1996, Steel, 2007, Van Eerde, 2003).

This can be explained by the fact that males and females have a close view of the goal of procrastination, there is no difference, as they are hit by the theory of psychological combustion, they live in one rural community, under the same conditions so that they are assigned to the same tasks duties, and additional work, they are exposed to the same criteria in the performance of tests, under the same psychological, temporal and methodological pressures, as well as the large size of some curricula, all these reasons lead to no differences between them in the behavior of procrastination academic tasks. 
It can also be argued that there are no differences between males and females in deferring academic assignments. The reasons for deferment may be different in both males and females, and this is consistent with the results of both (Freih Owaid Al-Enezi and Mohammed Daghaim Al-Dughaim, 2003).

The large number of distractors from listening to television programs, practicing sports hobbies, and others makes both males and females postpone their assignments in the same way and with the same degree.

As well as the flames of the January 25 revolution, which burned the hopes of male and female students, for example: high school students who went to watch the events of the football match in Port Said province indicate the great tragedy, where statistics show that more than twenty school students High school students were killed, which in turn led the students to become preoccupied with the revolution and its events, which led them to procrastinate their assignments, and the work assigned to them.

\section{The fourth hypothesis}

There are no statistically significant differences in the scale of Academic Tasks Procrastination due to the grades (1/2/3) in general secondary school students. To confirm the validity of this hypothesis, the researcher used the One-Way ANOVA test, to calculate the statistical significance of the differences between the averages of students' grades in deferral of academic tasks, from grades (1/2/3) secondary school students. See Table 6.

Table 6. Anova analysis test of differences between averages of college grades among high school students in the Academic Tasks

Procrastination

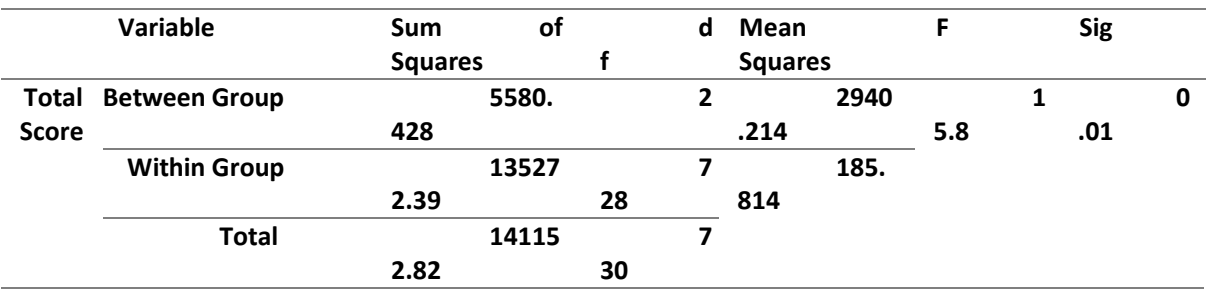


From table 6, the results of the previous table show that the fourth hypothesis is partially validated, as the results indicate that:

- There are statistically significant differences at the level of significance (05.0) between the average grades of students of grades (first and second) in the total score on the scale of procrastination academic assignments in favor of the average grades of second grade secondary students.

- There are statistically significant differences at the level of significance (05.0) between the scores of the first, second and third grade students in the total score on the procrastination of academic assignments in favor of the average scores of the third secondary students.

- There are no statistically significant differences between the average scores of the second and third grade students in the total score on the procrastination of academic assignments.

The results of previous research, the results of this hypothesis are consistent with those of Van Erede (2003: 1409) and Rosario et al. (Rosário et al., 2009: 122-124). Their research results indicate that academic procrastination levels rise with grade level, meaning that academic postponement is positively correlated with grade level (closely related to age), and that the greater the number of siblings, the more procrastination, and this also suggests that older siblings can be models For the procrastination behaviors of their younger siblings. Its results are also partially consistent with the results of Balkis and Duru (Balkis \& Duru, 2009: 23), the results of the correlation analysis showed that there is a statistically negative correlation between deferral behavior and age, that is, with age the level of academic deferment behavior decreases. Its findings are consistent with the results of the Yong research (Yong, 2010: 62), while the results of this hypothesis differ with those of Ferrari et al. (Ferrari et al., 2009: 302) and research (Mr. Abdel Dayem Abdel 
Salam, 2010: 50). ), And research (Fayqa Ahmed Abdel Azim, 2011).

This is due to the fact that second-graders are more burdened with assignments than first-graders. This is also because second-graders were part of the old system, which is a year of high school (secondary school). The students were frustrated by two important factors: First, that the total grades do not fall within the general secondary school grades, and secondly, it became a year of rest before entering the secondary school certificate next year.

This is also due to the fact that third-graders are required to complete their assignments and work at a limited time by their teachers in the classroom environment, as well as additional work on the part of the family. They find that they have many psychological pressures, especially the so-called (private lessons), which The student must respect and give in to the teacher in the performance of his assigned duties, but things go exactly the opposite, we find the student enjoys his time at the expense of the performance of his duties, so postponed to a later time, with a sense of distress, anxiety and uneasiness to delay it, because he knows very well that his parents will reproach him On it. The first grade students moved from the previous stage (preparatory stage) to another stage (secondary stage), This is a new stage for them, they want to achieve themselves, and this makes them perform their duties required of them, and there is another reason, that the performance of those duties and assignments are linked to the so-called (work of the year), and therefore fear the first grade students to be punished by their teachers, so they accomplish their duties.

\section{Conclusion}

Based on the results of the current research on the importance of the two research variables (perspective of the future time - Academic Tasks Procrastination) and the need to research the relationship between them, the researcher makes 
some recommendations that can highlight the role of these variables in the life of the individual and these recommendations lie in:

- The need for parents to pay attention to direct contact, to benefit from the guidance of the school administration, especially psychologists and social workers, and not to focus too only on the achievement of marks and neglect of other aspects.

- Holding meetings and workshops in schools to which specialists are called, in the presence of students to inform them of all new in all specialized fields.

- To open up the prospects for work as much as possible for young people, so that they can achieve themselves, develop the spirit of belonging to this country, and keep them away from pessimism from the future, they are the pillars of this country and its building.

- The need to educate high school students and recognize the value of time that should be used to achieve their future goals and aspirations.

- Enriching curricula at different levels, particularly secondary subjects that contribute to raising levels of professional and academic ambition, and help to develop a future perspective among young people.

- Educating young people about their future by identifying their real potential, and teaching them the skills of planning for the future on sound scientific foundations, so that young people do not fall prey to their ambitions and unrealistic future directions.

- Develop a future plan to reduce the worsening of youth unemployment, enhance their positive outlook, and reduce the negative outlook for the future.

- The educational and educational process must work on the development of the curriculum so that it does not rely solely 
on the mental aspect and neglect the emotional aspect of the learner.

- Contributing to the development of mentoring and therapeutic programs to develop the future direction of time, which may contribute to mitigating the effects of the negative procrastination of academic tasks on the achievement of students

- We should benefit from modern standards in scientific research and work to develop them through field application to different categories and environments of students and take advantage of data and results for the benefit of the educational process.

A proposed program to overcome the procrastination of academic tasks among high school students, and the first and most important step to overcome it is the full commitment of the procrastinator and convincing him not to procrastinate any work, and to be believe in: "Do not procrastinate today's work till tomorrow," knowing that this is not an easy matter because procrastinators need to develop skills to help them achieve their goals

\section{References}

- AKINSOLA, M. K., TELlA, A. \& TELLA, A. 2007. Correlates of academic procrastination and mathematics achievement of university undergraduate students. Eurasia Journal of Mathematics, Science \& Technology Education, 3, 363-370.

- ASIKHIA, O. A. 2010. Academic Procrastination in Mathematics: Causes, Dangers and Implications of Counselling for Effective Learning. International education studies, 3, 205-210.

- ATHAWALE, R. 2004. Cultural, gender and socio-economic differences in time perspective among adolescents. University of the Free State.

- BALKIS, M. \& DURU, E. 2009. Prevalence of Academic Procrastination Behavior Among Pre-Service Teachers, and its 
Relationship with Demographics and Individual Peferences. Journal of Theory \& Practice in Education (JTPE), 5.

- BOSATO, G. N. 2001. Time perspective, academic motivation, and procrastination.

- BROWNLOW, S. \& REASINGER, R. D. 2000. Putting off until tomorrow what is better done today: Academic procrastination as a function of motivation toward college work. Journal of Social Behavior and Personality, 15, 15-34.

- DALTREY, M. 1982. The development and evaluation of a future time perspective instrument (Doctoral dissertation, University of Colorado at Boulder, 1982). Dissertation Abstracts International, 43, 2315B.

- DEYLING, E. A. 2008. The effect of priming death anxiety on future time orientation and procrastination.

- FERRARI, J. R., ÖZER, B. U. \& DEMIR, A. 2009. Chronic procrastination among Turkish adults: Exploring decisional, avoidant, and arousal styles. The Journal of social psychology, $149,402-408$.

- GREENE, A. L. 1986. Future-time perspective in adolescence: The present of things future revisited. Journal of youth and adolescence, 15, 99-113.

- HEIMBERG, L. K. 1963. The measurement of future time perspective.

- HONORA, D. T. 1998. Future time perspective and academic achievement: How low-income African American adolescents view the future.

- HUSMAN, J. \& SHELL, D. F. 2008. Beliefs and perceptions about the future: A measurement of future time perspective. Learning and Individual Differences, 18, 166-175.

- JARADAT, A.-K. M. \& ROST, D. H. 2004. Test anxiety in jordanian students: Measurement, correlates and treatment. Universitat Marburg Vorgelegt von.

- JIAO, Q. G. \& ONWUEGBUZIE, A. J. 1999. I'll Go to the Library Tomorrow: The Role of Procrastination in Library Anxiety. 
- KEEGAN, P. M. 1986. Relationships among ego identity status, moral development and future time perspective in late adolescence. Boston University.

- LASANE, T. P. \& JONES, J. M. 2000. When socially induced temporal myopia interferes with academic goal-setting. Journal of Social Behavior and Personality, 15, 75.

- LEEKS, K. D. 2006. An examination of sexual risk behaviors and future time perspective among African American female juvenile detainees, The University of Alabama at Birmingham.

- LIU, K. 2010. The relationship between academic procrastination and academicachievement in Chinese university students, State University of New York at Buffalo.

- MCINERNEY, D. M. 2004. A discussion of future time perspective. Educational Psychology Review, 16, 141-151.

- MELLO, Z. R., BHADARE, D. K., FEARN, E. J., GALAVIZ, M. M., HARTMANN, E. S. \& WORRELL, F. C. 2009. the Window, the River, and the Novel: Examining Adolescents 'Conceptions of the Past, the Present, and the Future. Adolescence, 44.

- MELLO, Z. R. \& WORRELL, F. C. 2006. The relationship of time perspective to age, gender, and academic achievement among academically talented adolescents. Journal for the Education of the Gifted, 29, 271-289.

- ÖZER, B. U., DEMIR, A. \& FERRARI, J. R. 2009. Exploring academic procrastination among Turkish students: Possible gender differences in prevalence and reasons. The Journal of social psychology, 149, 241-257.

- PADAWER, E. A., JACOBS-LAWSON, J. M., HERSHEY, D. A. \& THOMAS, D. G. 2007. Demographic indicators as predictors of future time perspective. Current Psychology, 26, $102-108$.

- PEETSMA, T. \& VAN DER VEEN, I. 2011. Relations between the development of future time perspective in three life domains, investment in learning, and academic achievement. Learning and Instruction, 21, 481-494.

- PEETSMA, T. T. 2000. Future time perspective as a predictor of school investment. Scandinavian Journal of Educational Research, 44, 177-192. 
- PHAN, H. P. 2009. Amalgamation of future time orientation, epistemological beliefs, achievement goals and study strategies: Empirical evidence established. British Journal of Educational Psychology, 79, 155-173.

- PRICE, B. J. 2009. Differentiating future time perspective and future anxiety as distinct predictors of intimate partner violence. Northern Illinois University.

- REASINGER, R. \& BROWNLOW, S. 1996. Putting Off until Tomorrow What Is Better Done Today: Academic Procrastination as a Function of Motivation toward College Work.

- RODRIGUEZ, M. 1998. Future time perspective and academic achievement level among Puerto Rican children.

- RONAN, N. M. 1997. The relationship between future time perspective and breast self-examination in young adult women.

- ROSáRIO, P., COSTA, M., NúñEZ, J. C., GONZáLEZ-PIENDA, J., SOLANO, P. \& VALLE, A. 2009. Academic procrastination: Associations with personal, school, and family variables. The Spanish journal of psychology, 12, 118-127.

- SCHMIDT, R. W., LAMM, H. \& TROMMSDORFF, G. 1978. Social class and sex as determinants of future orientation (time perspective) in adults. European Journal of Social Psychology, 8, 71-90.

- SEYMOUR, R. 1992. Constructing a personal future time perspective.

- SHELL, D. F. \& HUSMAN, J. 2001. The multivariate dimensionality of personal control and future time perspective beliefs in achievement and self-regulation. Contemporary educational psychology, 26, 481-506.

- SILVERMAN, J. L. 1996. The development in children of future time perspective.

- SIMONS, J., VANSTEENKISTE, M., LENS, W. \& LACANTE, M. 2004. Placing motivation and future time perspective theory in a temporal perspective. Educational Psychology Review, 16, 121139.

- SOLOMON, L. J. \& ROTHBLUM, E. D. 1984. Academic procrastination: Frequency and cognitive-behavioral correlates. Journal of counseling psychology, 31, 503. 
- STAHL, S. T. 2009. Health promotion during midlife: The influence of internal health locus of control and future time perspective, West Virginia University.

- STEEL, P. 2007. The nature of procrastination: A meta-analytic and theoretical review of quintessential self-regulatory failure. Psychological bulletin, 133, 65.

- TUCKMAN, B. W. 1990. Measuring Procrastination Attitudinally and Behaviorally.

- VAN EERDE, W. 2003. A meta-analytically derived nomological network of procrastination. Personality and individual differences, $35,1401-1418$.

- WOOD, K. 1998. The relationship of impulsivity and extension of future time perspective in adolescents.

- YONG, F. L. 2010. A study on the assertiveness and academic procrastination of English and communication students at a private university. American Journal of Scientific Research, 9, 6271.

- ZIMBARDO, P. G., KEOUGH, K. A. \& BOYD, J. N. 1997. Present time perspective as a predictor of risky driving. Personality and Individual Differences, 23, 1007-1023. 